\title{
Feedback and the use of land for parking
}

\author{
Lewis Lehe \\ University of California, Berkeley
}

lewis500@berkeley.edu

\begin{abstract}
Land-use patterns are often the result of feedback effects in which one agent's decision both influences and is influenced by urban form. This paper argues that such feedback — of a positive or negative kind — could plausibly arise in the provision of off-street parking. A stylized model is used to illustrate feedback in the case of bundled parking, to note how such feedback may change a neighborhood in the long run and to analyze several policies. A theme is that feedback opens the door to surprising effects that are hard to predict from the status quo.
\end{abstract}

Article History:

Received: July 2, 2015

Accepted: June 23,

2016

Available online: December 12, 2016

\section{Introduction}

Off-street parking is among the most heavily regulated features of the built environment. In particular, parking minimums-rules requiring developers of new buildings to supply off-street parking in some proportion to the amount of built structure-have been nearly ubiquitous in the United States for decades (Ferguson 2004; Jakle and Sculle 2004). But the tide may be turning, and a drive to relax parking minimums is gaining traction. This trend invites questions about how cities would change if today's rules were liberalized or-as proposed in Barter (2010) — replaced by a new regime. ${ }^{1}$ A robust and growing literature on parking seeks to provide answers and bring clarity to these questions.

Part of the parking literature is concerned with the actions of individual developers and landowners. Would they really supply much less parking if permitted? Li and Guo (2014) use as a natural experiment a campaign of parking reform-both the elimination of minimums and, in some places, the imposition of maximums-carried out in London during the early 2000s. Comparing nearby developments before-and-after, the authors estimate reforms reduced off-street parking by 0.76 spaces per unit, or 49 percent, and that eliminating minimums was more important than imposing maximums. Similarly, Manville (2013) looks at Los Angeles projects that take advantage of an ordinance change for the reuse of historic buildings, and find developers include less parking when allowed. McDonnell et al. (2011) find that 18 of 38 residential projects surveyed in Queens provided exactly the minimum number of parking spaces, which would be a coincidence were mandates not the limiting factor. Taking a more economic approach, Cutter and Franco (2012) ask whether the marginal parking space adds more value to the structure with which it comes bundled than it costs to provide. For six property types in suburban Los Angeles, the marginal space does not appear to pull its weight, suggesting it exists for compliance.

\footnotetext{
${ }^{1}$ For a more thorough discussion of the economics of parking, see Inci (2014).

Copyright 2016 Lewis Lehe.

doi: $10.5198 /$ jtlu.2016.835

ISSN: 1938-7849 | Licensed under the Creative Commons Attribution - NonCommercial License 3.0.

The Journal of Transport and Land Use is the official journal of the World Society for Transport and Land Use (WSTLUR) and is published and sponsored by the University of Minnesota Center for Transportation Studies.
} 
There is also strand of thought in the parking literature that takes what might be called the "neighborhood perspective." A theme is that, paved surfaces being neither origins (such as homes) nor destinations (such as shops, cafes, bars, groceries, offices, social facilities) unto themselves, off-street parking takes space from the enlivening land uses that make a place walkable. There is a competition between parking and floorspace. Weinberger et al. (2010) argues that, due to parking minimums, "The walking environment is undermined and the distance between destinations increases." Mukhija and Shoup (2006) agree: "Parking lots and garages tend to interrupt the streetscape, expand the distances between destinations, and undermine walkability." Taken far enough, parking minimums become what Willson (1995) calls "tacit policy for automobile use and urban sprawl." On the other hand, implicit in the rules themselves is another argument from the neighborhood perspective: without abundant off-street parking, vehicles will crowd the streets and overflow among neighbors' private lots.

This paper aims to theoretically link the two perspectives for a particular urban environment. Under consideration are city neighborhoods meeting two criteria: First, the amount of off-street parking can feasibly affect the neighborhood's walkability and crowding. Excluded, then, are places where land is so lightly developed that parking does not meaningfully limit density, and where on-street parking is plentiful for any level of off-street parking. Second, the neighborhood is subject to sequential land-use change in which lots are developed or redeveloped on occasion. When the time is right, a propertyowner or developer may rebuild a dilapidated house, construct new apartments on an under-used lot or undertake a small finesee, such as turning a garage into an in-law unit. Both student neighborhoods and the older, residential areas of American cities are often good examples of the sort of area we have in mind.

For a neighborhood of this kind, the paper explores the idea that there may plausibly arise a "feedback loop" between individual decisions and neighborhood outcomes. This feedback loop is a relationship of mutual influence: The individual developer's choice of how much off-street parking to supply influences neighborhood characteristics, which, in turn, influence that choice. Other features of urban life and land-use are rich in such chicken-and-egg links between gestalt properties and individual choices. An entrepeneur opens the tenth bar in a popular nightlife district because the crowds are there, and people go there for a night out precisely because there is such a variety of bars. It may be profitable for planners to consider feedback with respect to the parking supply, too.

One reason to look at feedback in parking is to enrich the conceptual vocabulary by which parking is understood. Urban neighborhoods can evidently function with widely different parking intensitiesfrom relative parking deserts in Philadelphia and Boston to lands of milk and honey in Las Vegas and Phoenix. An appreciation of feedback invites interesting questions about this state of affairs. With parking minimums liberalized, is it possible that a parking-abundant, mildly-walkable neighborhood could, over the course of decades, become more like a parking-scarce, highly-walkable neighborhoodthat a neighborhood in, say, Atlanta could become a little more like one in, say, Pittsburgh?

A second reason is to recognize that policy results can be hard to predict from even a thorough study of the status quo. Suppose, for instance, that a planner surveys recent projects in a neighborhood and learns that developers would have rather built only about half the spaces required by law. It is tempting to deduce that, if the law were abolished, new projects would in fact turn out to have about half as many spaces. But while today's developers may build projects with only half as many spaces, once enough of them do so they will have collectively somewhat changed the neighborhood character, made it denser. Consequently, future developers may want to supply either more spaces or fewer. Perhaps developers will come to see parking as an underserved niche they can enter profitably. On the other hand, perhaps they will decide the neighborhood is becoming the sort of walkable place where people can make do with considerably less parking. These later decisions, in turn, will "feed back," shaping still later ones.

The paper explores the above logic in the following way: First, Section 2 discusses qualitatively the idea of a feedback loop in parking provision-what mechanisms might drive it and to what effect. Next, borrowing an approach from economics, Section 3 proposes a particular, stylized model 
in which feedback arises. The model is used to illustrate the path of the neighborhood under positive and negative feedback, the concept of equilibrium and implications for policy. Section 4 concludes.

\section{The concept of feedback}

The concept of a feedback loop has wide purchase across physical and social sciences. In engineering, it describes a system whose output is also one of its inputs-e.g., when the microphone picks up the sound of the speaker to which it is connected. Here, the feedback loop describes a relationship of causation between two quantities: (i) the amount of parking in a neighborhood; (ii) the amount of parking that individual property-owners or developers (hereafter referred to as "landlords") wish to provide upon redevelopment. One direction of causation is arithmetically true: how much parking individuals decide to provide affects the aggregate parking supply. The other direction of causation hinges on a question: how does the neighborhood influence the individual? Depending on the nature of that influence, feedback can be of either a "positive" or "negative" character.

\subsection{Positive feedback}

Positive feedback in general describes a process that is self-reinforcing-such as the example of a microphone cited above. It has long been of use to social scientists in explaining the multiple equilibria, path dependence, tipping points and other interesting phenomena observed in real societies-particularly the remarkable complexity and discontinuity of human geography. Widely-cited examples include racial segregation (Schelling 1971), educational segregation (Benabou 1993), differences in the frequency of riots among places (Granovetter 1978), and manufacturing belts (Krugman 1990).

Positive feedback here means a rise in the neighborhood's parking supply makes the individual landlord want to provide more parking. The converse holds, too: the scarcer parking becomes, the less the landlord wants to supply. Why should this happen? Setting aside for now facts about crowding and a market for parking, the force driving positive feedback could be the same one that has invited concerns about a surfeit of parking: its effect on walkability, on the pedestrian vibrancy of the place.

It is hard to say with any precision how much land in cities is devoted to parking, and even statistics widely quoted may be unreliable (Manville and Shoup 2005). Looking at several studies of different cities, McCahill and Garrick (2014) report estimates that between 10 and 40 percent of CBD land is parking. In any case, parking clearly consumes much land that could be otherwise devoted to origins or destinations. Thus, its prominence in the landscape constrains the count of destinations reachable from an origin by a reasonably short trip on foot or by bike. And by the same token, the aggregate amount of land devoted to parking also constrains the number of customers who can be pedestrian patrons of a destination.

There are several ways that walkability could reasonably cause a landlord to devote less space to parking and more to another use. Perhaps floorspace rents and parking rents rise as walkability increases, but floorspace does so more quickly. Or, per the Cutter and Franco (2012) model in which parking enhances the floorspace with which it comes bundled, parking might not "pull its weight" as much in a walkable area; it might not add enough value relative to its cost and the floorspace it displaces. Lastly, on land that is owner-occupied, a rise in walkability might lead the owner to do without the third car and build an extension over part of the driveway. And even when current owners do not plan these alterations, buyers who do wish to make them will raise their bids as walkability rises.

Note the difference between the sort of positive feedback advanced here and another, more "topdown" conception. Jacobs (1961, p. 350) explicitly cites positive feedback to explain the "erosion of cities" by automobile space-including parking. The principals in Jacobs' story are bureaucrats and civic leaders who endlessly convert land from other uses to parking and streets. Positive feedback describes the ironic way their interventions frequently wind up making traffic worse, leading the interventions to be iterated. Similar theories of positive feedback at the government level-though not 
necessarily stated in the language of feedback-appear in Shoup (2005, Ch. 5). The question here, by contrast, is what happens if the government strengthens or weakens a certain policy and lets things evolve, not what happens if the government keeps ramping up or down the policy. Change occurs as a side-effect of uncoordinated private action. The actors are landlords uninterested in, and likely ignorant of, what their own parking does to urban form.

\subsection{Negative feedback}

Negative feedback generally describes a process that is self-stabilizing, wherein a deviation in the output tends to undermine itself. An example is the body's temperature control system: when temperature deviates from the body's target level, the body takes note and either sweats or shivers to return to the target. Negative feedback here means a rise in the parking supply discourages the individual landlord from providing parking, whereas a fall inclines the landlord to provide more.

An obvious mechanism for negative feedback is supply-and-demand in a place where parking is traded as a priced commodity: a boost in supply sinks parking rents, muting the incentive to add parking; and a scarcity of parking in a dense neighborhood will raise the price of parking, making it profitable to provide. Where parking comes bundled with floorspace, negative feedback can still plausibly arise via crowding: on-street parking becomes harder to find when the neighborhood lacks off-street parking, because people park on the street more often. Reasonably, this crowding means that the marginal parking spot adds more value to the bundled floorspace than when an on-street space is always ripe for the taking nearby. Thus, crowding makes profitable a higher ratio of parking to rentable floorspace.

\section{Economic model}

Above, Krugman (1990) was mentioned as a famous application of positive feedback concepts in geography. It is a purely theoretical study. Decribing its goals, Krugman (2011) says he set out to create, "a model that was not intended to be realistic, indeed was aggressively unrealistic, but would serve as a demonstration." This section, similarly, works through a highly stylized model of parking provision. While this tack is unusual for the planning literature, it has advantages that compensate for strong assumptions. The model serves as an example-like the frictionless surface of introductory physicsthat is easy to work with. It permits a graphical analysis in which certain qualitative ideas-such as equilibrium, change and whether requirements bind-can be spoken of concretely and memorably. And to the degree the model is unrealistic, it is at least plainly so.

Section 3.1 establishes the basic assumptions of the model and shows how landlords decide how much on-street parking to provide. It is a Cutter and Franco (2012) situation in which parking adds value to bundled floorspace. The bundled case is chosen because it is more interesting than the simple mechanics of supply-and-demand, and because so much parking is bundled. Weinberger et al. (2010) reports that developers have even tried to evade a San Francisco initiative that requires unbundled parking, by offering special pricing to owners of associated units. Sections 3.2 and 3.3 model assumptions about demand that lead to positive and negative feedback, respectively. In Sec. 3.4, we discuss how equilibria and long-term change happen in the model's context. Lastly, Sec. 3.5 looks at several policies.

Note that a real neighborhood can and likely will have both forces of positive and negative feedback at the same time. We treat the all-or-nothing situations only for clarity of exposition.

\subsection{Basic assumptions}

Privately-owned land is divided into small parcels owned by landlords who are also, potentially, developers. It is assumed that all structures are $\beta$ stories tall, that landlords provide only what yardspace is mandated by setback rules and that parking is at ground level beside the structure. See Figure 1 for a 
diagram of a parcel, in which the trees are setbacks. Consequently, the developable area of the neighborhood is split between off-street parking and structures, and for the neighborhood to gain $x \mathrm{sq}$. $\mathrm{ft}$. of parking it must lose $\beta x$ sq. $\mathrm{ft}$. of floorspace. Let the parking ratio, $p$, be the ratio of parking space to floorspace on an individual parcel. It follows that $1 /(1+p \beta)$ is the fraction of a parcel's developable land devoted to structure, while $p \beta /(1+p \beta)$ is the parking fraction. Let $\bar{p}$ stand for $p$ 's aggregate equivalent: the ratio of parking to floorspace for the whole neighborhood.

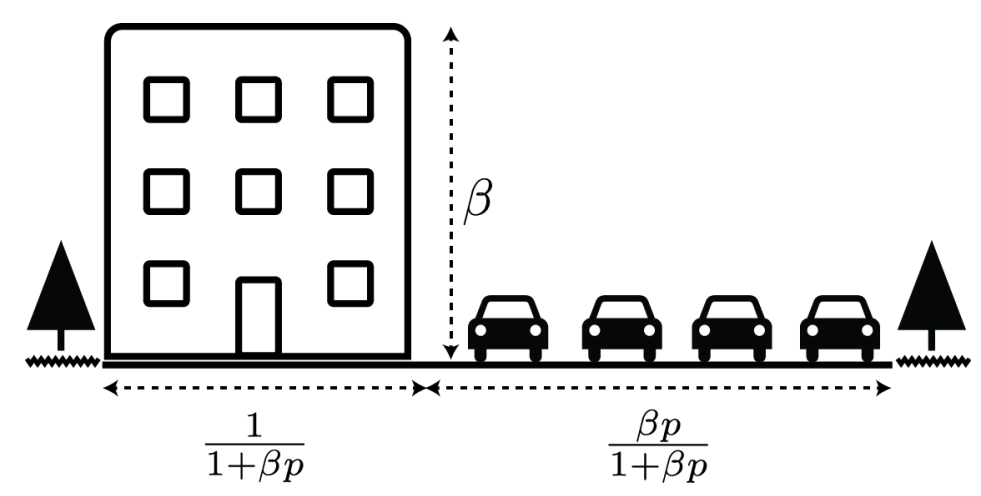

Figure 1: division of a parcel

The "rent" per unit area of floorspace is $R$. This is not a literal rent; it is the amortized return after costs. ${ }^{2}$ The rent depends partly on $p$, the parking ratio of a single parcel. Parking cannot be practically rented or sold as a commodity; rather, it comes bundled with floorspace for use by the parcel's occupants. The job of parking is to boost the rent of floorspace, and it is assumed to do so with diminishing marginal returns. Thus, we can write rent as a function $R(p)$, whose derivatives have the signs $\partial R / \partial p>0$ and $\partial^{2} R / \partial p^{2}<0$.

Landlords choose $p$ to maximize profit. Since only floorspace earns money, and the amount of floorspace per unit area of land is $\beta /(1+p \beta)$, it follows that profit, $\pi$, per unit area of land, is

$$
\pi(p) \equiv \frac{\beta}{1+p \beta} \cdot R(p)
$$

This expression shows the landlord's fundamental trade-off when parking is bundled: adding parking (raising $p$ ) boosts the rent but at the cost of losing floorspace, which appears as an increase in the denominator. The derivatives of $R(p)$ give $\pi(p)$ the hump shape in Fig. 2. There is a unique, profit-maximizing parking ratio, $p^{*}$. As $p$ grows ever larger, profit falls off to zero because there is no floorspace to rent out at all. In Fig. 2 , the peak occurs at a non-zero $p^{*}$, but it is also possible that it is optimal to provide no parking at all.

In addition, the rent of floorspace depends—directly or indirectly—upon the neighborhood parking ratio $\bar{p}$. Depending on how it does so, a change in $\bar{p}$ may change the profit-maximizing parking ratio, $p^{*}$, that the landlord would like to have. Graphically, this means that a change in $\bar{p}$ shifts the peak of $\pi(p)$ to the right or left. If we calculate the optimal parking ratio, $p^{*}$, for each aggregate ratio, $\bar{p}$, we wind up with a best-response function $p^{*}(\bar{p})$. The best-response function tells what parking ratio a landlord would like, given the aggregate ratio is $\bar{p}$. When there is positive feedback, $p^{*}(\bar{p})$ rises with $p$; the peak of $\pi(p)$ shifts rightward as $\bar{p}$ increases. When there is negative feedback, $p^{*}(\bar{p})$ falls with $p$; the peak of $\pi(p)$ shifts leftward as $\bar{p}$ increases.

\footnotetext{
${ }^{2}$ Since only returns - the margin of income over costs-matter to the developer's decision, treating real rents and costs would add complication without obtaining different results.
} 


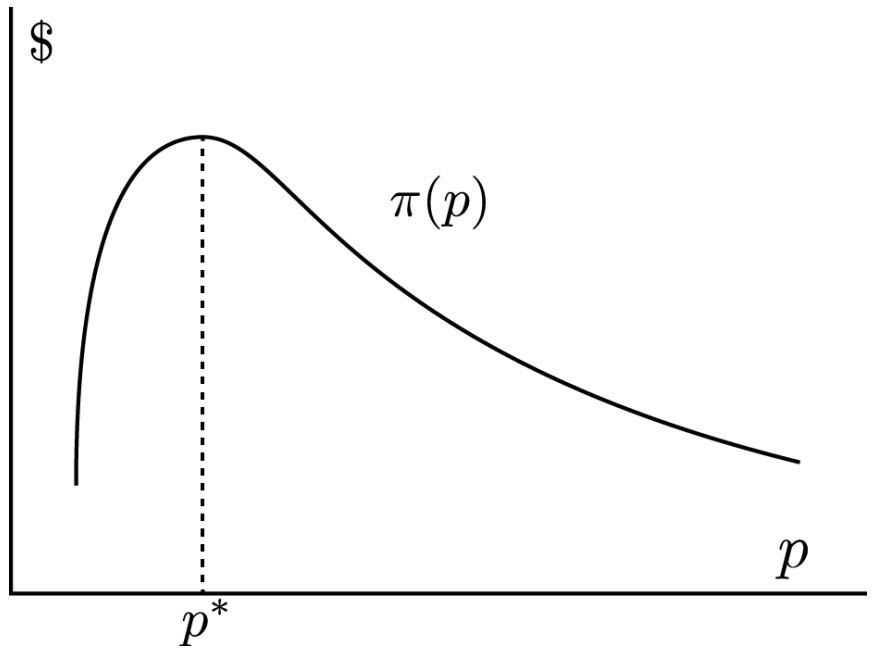

Figure 2: profit function $\pi(p)$

\subsection{Positive feedback assumptions}

The story we will tell to obtain positive feedback is that, when a neighborhood is dense in destinations, rents become high enough-per unit area of floorspace though not necessarily per apartment or shop - that a lower parking ratio is optimal. Closing the loop is the fact that, when the neighborhood gains floorspace, it gains occupants who can financially support a richer ecosystem of destinations.

Suppose the count of walkable destinations in the neighborhood, $w$, rises with aggregate floorspace in the following way: for every unit of floorspace beyond a minimum area $\alpha$, the neighborhood gains one destination. It is assumed that the destinations themselves-at least the ones who are drawn in by more occupants-do not consume a very significant fraction of the neighborhood's area. Let $A$ be the area of developable land of the neighborhood, such that $\beta A 1+\bar{p}$ is the aggregate supply of floorspace. We may write a function

$$
w(\bar{p}) \equiv \max \left\{0, \frac{\beta A}{1+\beta \bar{p}}-\alpha\right\},
$$

where the max operator precludes negative destinations.

Next, suppose rent is given by the function

$$
R(p, w) \equiv R_{0}-\frac{1+\exp \left(-w^{2}\right)}{1+\beta p} .
$$

This function has been chosen to obtain illustrative results but is not especially meaningful in its own right. $R_{0}$ is a positive constant that can be thought of as a sort of "base rent." The second term rises in a diminishing way with $p$ (so that tenants value parking), and it rises with $w$ (so that tenants value access to destinations). To find the best-response function, we plug $R(p, w(\bar{p}))$ into (1) and seek the profit-maximizing $p$ for every $\bar{p}$. For the right values of $A, R_{0}, \beta$ and $\alpha, p^{*}(\bar{p})$ is $S$-shaped. Such a curve appears in Figure 3 alongside the $45^{\circ}$ line $p=\bar{p}$. Positive feedback is manifest in $p^{*}(\bar{p})^{\prime}$ s positive slope.

\subsection{Negative feedback assumptions}

The story we will tell to obtain negative feedback is that on-street and off-street parking are substitutes, and that, as $\bar{p}$ declines (as the neighborhood becomes denser in floorspace and scarcer in parking), 


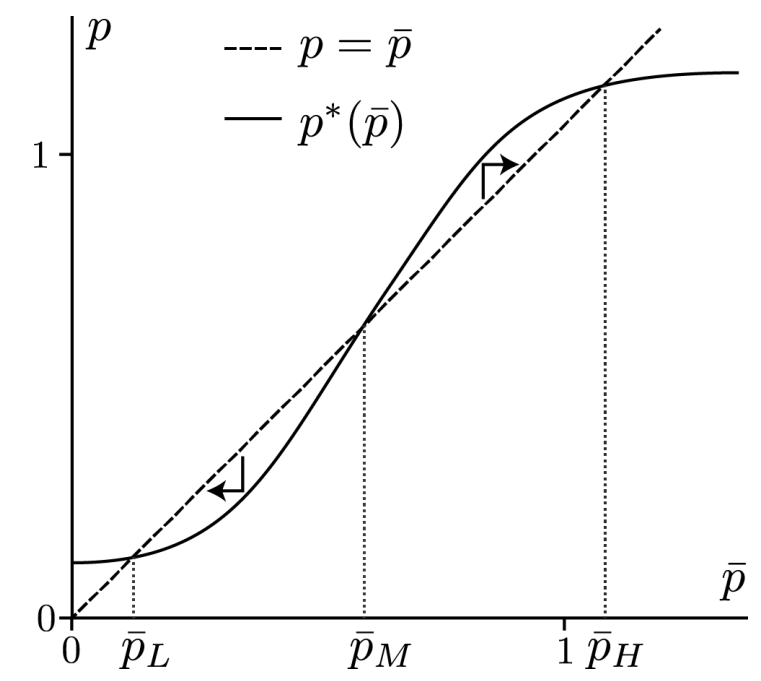

Figure 3: best-response curve with positive feedback;

$$
R_{0}=1.8, \alpha=2, A=4.7, \beta=1
$$

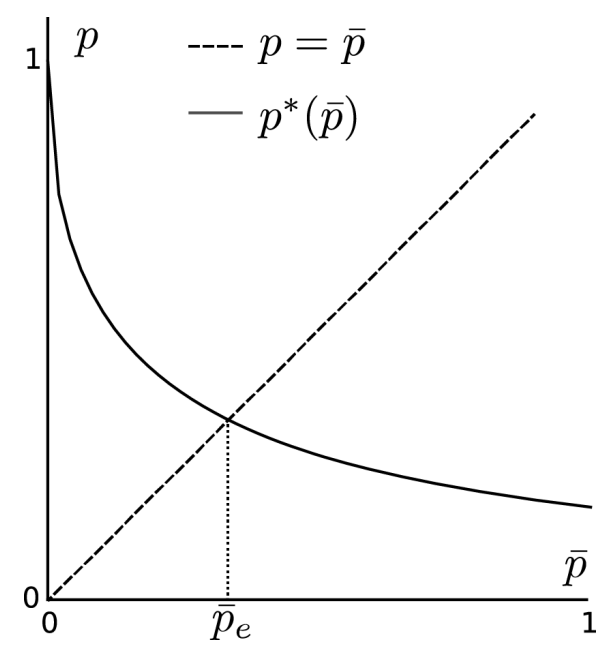

Figure 4: best-response curve with negative feedback

finding on-street parking involves more cruising and a longer walk. This crowding causes the rent to rise and fall with $\bar{p}$. Specifically, let rent be given by

$$
R(p, \bar{p}) \equiv p^{1 / 2}+\bar{p}^{1 / 2}
$$

Each term captures the positive, but marginally diminishing, value of on-street and off-street parking. Figure 4 shows the best-response function $p^{*}(\bar{p})$ derived from (4), again when $\beta=1$. Negative feeback is manifest in the negative slope of $p^{*}(\bar{p})$.

\subsection{Change}

Since a neighborhood's characteristics arise from the sum of individual decisions, redevelopment opportunities lead to the possibility of neighborhood-level change. An advantage of our formal model is clarity about how this change may occur. Three ideas are discussed: (i) how to predict the direction of change, (ii) equilibrium and (iii) stability. 
The process of change, of course, is liable to happen very slowly and possibly be subject to fits and starts. Buildings are very long-lived assets; they cannot be tailored in real-time to always fit what would be optimal to build today if the landlord were starting from scratch. But by the varied types of redevelopment we have proposed, it is possible to speak of general directions of change-densification, clearing out-without pretending that parking supply wavers like the stock of orange pulp in a warehouse.

\subsubsection{The direction of change}

To understand the direction of change, consider Figures 3 and 4 again. Whenever the line of the bestresponse function is below the $45^{\circ}$ line $p=\bar{p}$, it is true that $p^{*}(\bar{p})<\bar{p}$, which means the individual landlord chooses a below-average ratio. Granted that this is permitted, the redeveloping landlord will do so. And, just as the average height of a team falls when a shorter-than-average player joins, when one landlord chooses a less-than-average parking ratio, the aggregate ratio falls slightly. Therefore, if the neighborhood is ever found to have a $\bar{p}$ where $p^{*}(\bar{p})<\bar{p}$, then the on-going process of redevelopment will slowly bleed the parking supply. And when $p^{*}(\bar{p})>\bar{p}$, the neighborhood will take on parking, because landlords choose an above-average ratio.

A lesson is that whether the neighborhood gains or loses parking is not a matter of having "too much" or "too little" parking, relative to similarly-situated neighborhoods or to what intuition would suggest. Whether the neighborhood is liable to gain or lose parking depends on the forces at play for the particular parking ratio at which the neighborhood finds itself. Consider the neighborhood of Fig. 3 , the positive feedback case. If the neighborhood has a ratio between $\bar{p}_{L}$ and $\bar{p}_{M}$, then some parking will disappear every few years. But if it has even more parking than this, if it has a $\bar{p}$ between $\bar{p}_{M}$ and $\bar{p}_{H}$, then new parking will spring up. Thus, between these two intervals, adding to the parking supply raises the demand for parking.

\subsubsection{Equilibrium}

An equilibrium is said to arise when no landlord wants to change her parking ratio. This may happen in the model under two circumstances: First, nearly every landlord has nearly the same parking ratio, in which case $p \approx \bar{p}$ for every landlord. Second, the universal parking ratio is a value at which at which $p^{*}(\bar{p})=\bar{p}$. At ratios satisfying this condition, redevelopment does not change the aggregate.

Graphically, equilibrium parking ratios can be identified in our plots as the locations of intersection between the best-response curve and the $45^{\circ}$ line. There are three in the positive feedback case of Fig. 3: $p_{L}, p_{M}$ and $p_{H}$. There is only one, $\bar{p}_{e}$, in the negative feedback case of Fig. 4. Purely negative feedback can only allow one equilibrium, because, if the best-response curve always falls, then once it crosses the $45^{\circ}$ line it can never rise to cross again. Positive feedback enables infinitely many crossings, depending on how the best-response curve wiggles as it rises, though the particular case presented here involves just three.

\subsubsection{Stability}

While there may be many equilibria, only those that can survive a very slight deviation-such as a few landlords not exactly following the rules of our model - are called "stable." Stable equilibria in our examples are $\bar{p}_{L}$ and $\bar{p}_{H}$, from the positive feedback case, and $\bar{p}_{e}$, from the negative one. These are cases where the best-response function crosses the $45^{\circ}$ line from above, where $p^{*}(\bar{p})$ exceeds $\bar{p}$ to the left of the intersection and drops below $\bar{p}$ to the right. This sort of crossing means that, if the aggregate ratio $\bar{p}$ is slightly higher than $\bar{p}_{H}, \bar{p}_{e}$ or $\bar{p}_{L}$, then the neighborhood will lose parking and drop down to the equilibrium ratio; and if the aggregate ratio is slightly lower, then the neighborhood will gain parking and rise up to the equilibrium ratio. 
Equilibria that unravel easily are called "unstable." The middle ratio $\bar{p}_{M}$ is unstable. If $\bar{p}$ winds up slightly higher than $\bar{p}_{M}$, then landlords will begin to choose greater-than-average parking ratios, and they continue to do so as long as $p^{*}(\bar{p})>\bar{p}$. Change will continue until the stable equilibrium $\bar{p}_{H}$. Conversely, if $\bar{p}$ deviates just left of $\bar{p}_{M}$ (where $\left.p^{*}(\bar{p})<\bar{p}\right)$, landlords will provide a less-than-average amount until the neighborhood levels out at $\bar{p}_{L}$.

In reality, no neighborhood will sit in a stable or unstable equilibrium, however conceived, for very long. Tastes, costs and larger market forces are in constant flux, and their irregular tides mean, for our model, constant shifts in the $R$ and $p^{*}$ curves. Nonetheless, the concept of stability can be a useful ideal. A stable equilibrium, even one in motion, suggests what direction the neighborhood is likely to move even if it never quite stops. And the possibility of multiple stable equilibria highlights to the importance of history-dependence-that the neighborhood is only in its current state because it was there yesterday, not because the status quo is the only way things could have practically turned out without planning.

\subsection{Policies}

So far, Sec. 3 has set up a neighborhood and asked how it might be expected to change and to stop changing in the absence of policy. Fortunately, the model can usefully adapted to the formal analysis of policy, and doing so yields several insights. Below, three policies will be examined: (i) parking requirements, (ii) parking taxes and (iii) direct coordination. Somewhat more space is devoted to the effects of policies in the positive feedback case. The reason is that results of positive feedback are more nuanced, not necessarily more realistic.

\subsubsection{Parking requirements}

While parking minimums are most common, some places_-such as San Francisco and Manhattanhave maximums. These requirements can be treated as either floors or caps on the value of $p$ that a landlord is allowed to choose. Real parking requirements in many cases are written exactly so, as a number of spaces that must be provided per 1000 sq. $\mathrm{ft}$. of floorspace.

As is well known, just because there exists a requirement does not necessarily mean it has any meaningful effect on land-use. Requirements only bind - that is, the landlord only wishes to do something differently than he or she is allowed to-in certain cases. A minimum binds when landlords would like to supply less parking than allowed; a maximum, when they would like to supply more. Evidence of minimum parking requirements binding was mentioned in the introduction. The parking maximum in Manhattan must be binding for certain landlords, because they have organized to have it relaxed (Manville et al. 2013, p. 363).

Parking requirements are nested graphically in Fig. 5. A minimum $p_{\min }$ can bind if it falls where $p^{*}(\bar{p})$ is below the $45^{\circ}$ line $p=\bar{p}$. In this case, if every parcel has a parking ratio near the minimum (so that $\bar{p} \approx p_{\min }$ ), then landlords will want smaller ratios than $p_{\min }$. Similarly, a maximum $p_{\max }$ can bind when $p^{*}(\bar{p})$ exceeds $p=\bar{p}$.

This way of looking at mandates has two main lessons. First, in order for a requirement to actively bind, the neighborhood must somehow reach the point where individual landlords wish to break it. In Figure $5(\mathrm{~b}), p_{\min }$ is potentially binding, but if the neighborhood has settled in at the equilibrium $\bar{p}_{H}$ then landlords will gladly supply much more than $p_{\min }$. This is possible not only for this model but for any situation where there are multiple equilibria. What might be called a requirement's "bindingness," then, is not an essential feature of the requirement itself; it has power only in a specific history of a particular location.

Second, the long-run effect of a requirement may be substantially stronger or weaker than what the individual landlord's current point-of-view would suggest. The span $g$ on Figures 5(a) and 5(b) 


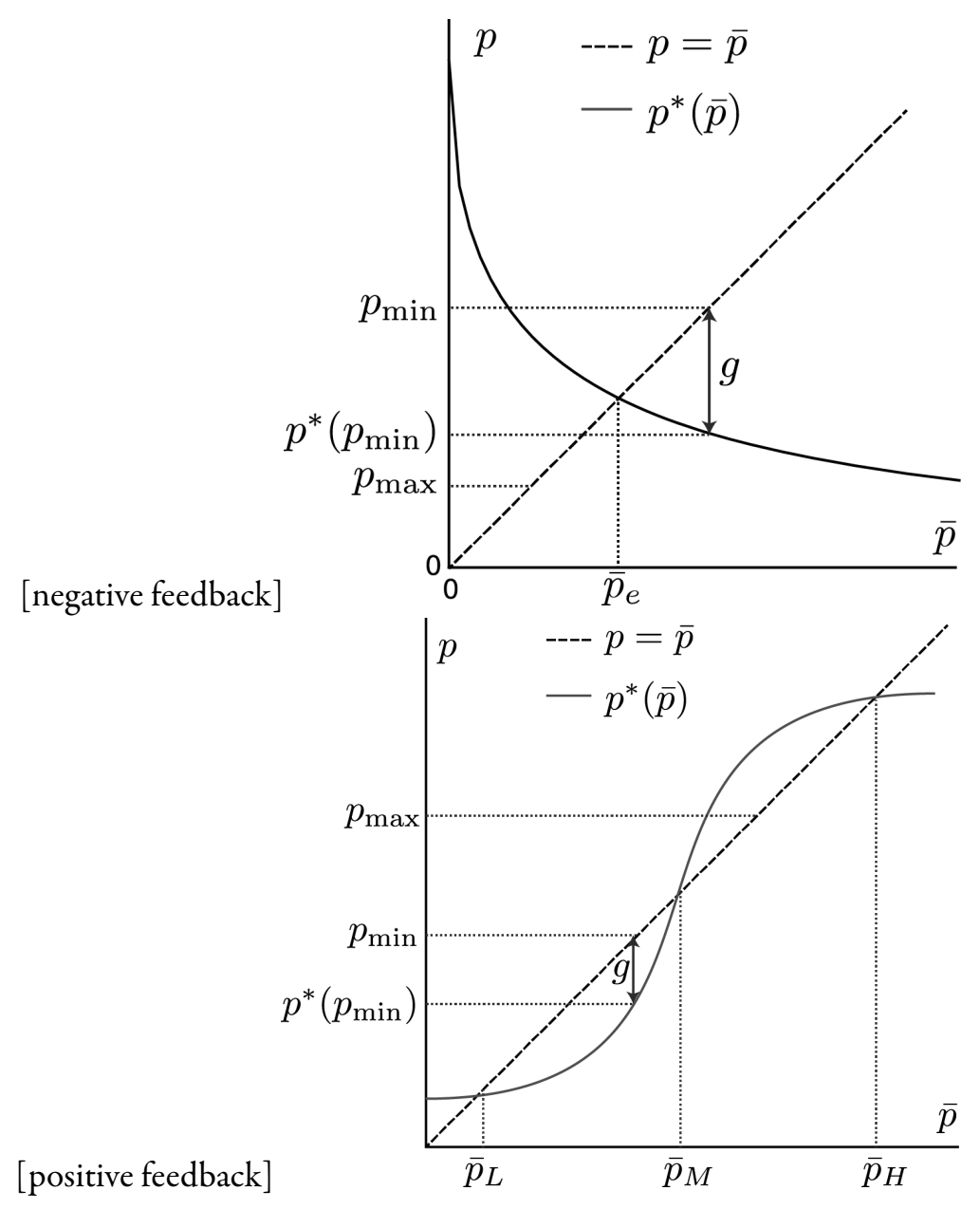

Figure 5: minimum parking requirements

measures the gap between $p^{*}\left(p_{\min }\right)$ and $p_{\min }$ : how much parking a landlord provides to meet the minimum when the neighborhood has settled at the minimum. In 5(a), landlords would rather supply much less parking (large $g$ ). But were the minimum abolished, the neighborhood would converge not to $p^{*}\left(p_{\min }\right)$ but to $\bar{p}_{e}$, which is much nearer to $p_{\min }$ than is $p^{*}\left(p_{\min }\right)$. Thus, the long-run effect with negative feedback is weaker than $g$ in the status quo. Some of the parking that one landlord decides not to provide will be provided by a different landlord. The long-run effect with positive feedback, on the other hand, may be much stronger than $g$. Figure 5(b) shows that, if the minimum were abolished, the conversion of parking to floorspace would compound until the neighborhood reached $\bar{p}_{L}$. As an example, suppose that, after the parking minimum in some neighborhood is weakened, some developers construct apartment complexes with many residents and little parking, and that the extra population draws a major grocery store. Once the grocery store is in place, future developers will be even less inclined to waste floorspace on parking, because rents will have risen somewhat, and customers with fewer cars will more often take an interest in the apartments.

\subsubsection{Parking tax}

A tax on parking area is advocated in Feitelson and Rotem (2004) as a means of internalizing driving externalities and the heat absorption and polluting runoff of parking surface. To include a tax in our models, let $\tau$ be the amount of the tax. Since the tax applies per unit area of parking, the developer 


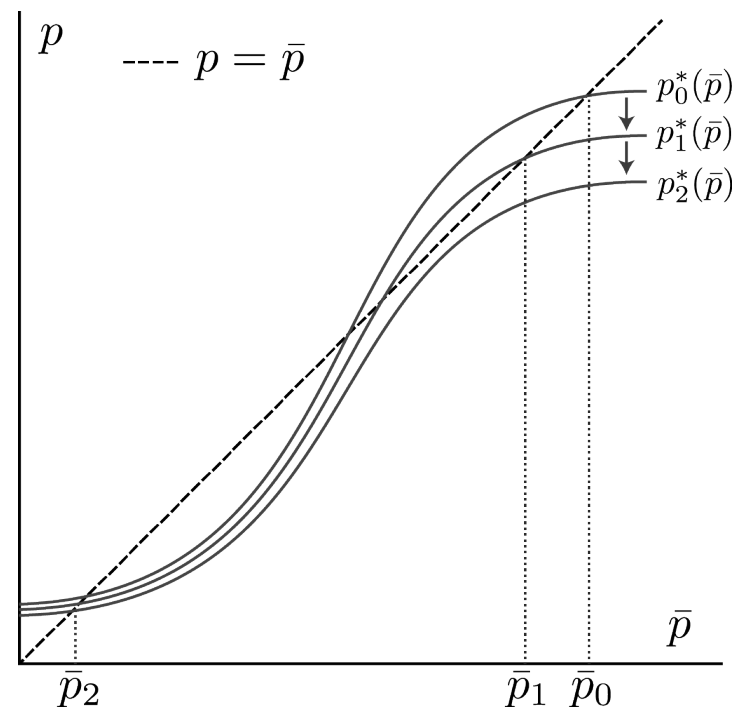

Figure 6: effect of parking tax on best-response

pays a tax on the parking fraction, $\beta p /(1+\beta p)$ of the parcel. Therefore, profit is

$$
\pi=R \cdot \frac{\beta}{1+\beta p}-\tau \cdot \frac{\beta p}{1+\beta p} .
$$

The best-response function $p^{*}(\bar{p})$ is then found in the usual way: by finding the profit-maximizing level of $p$ for every $\bar{p}$.

For both $R$ above, the tax shrinks $p^{*}$, which is probably unsurprising. More noteworthy is the fact that, with multiple stable equilibria, the size of the effect of the tax may jump when the tax rises only slightly. There can be a "threshold effect" or a "tipping point." Examples of neighborhood thresholds for other variables are reviewed in Quercia and Galster (2000).

To illustrate a threshold effect, Fig. 6 show the best-response curve for three levels of the tax in the positive feedback case. The neighborhood begins at the equilibrium $\bar{p}_{0}$ and with $\tau=0$, for which $p_{0}^{*}(\bar{p})$ is the best-response curve. When the tax rises slightly to $\tau_{1}$, the best-response curve falls to $p_{1}^{*}$, and, over time, the parking ratio falls to $\bar{p}_{1}$. The result is a somewhat, but not substantially, denser and more walkable neighborhood. When the tax rises again to $\tau_{2}$, the best-response curve shifts downward to $p_{2}^{*}(\bar{p})$. Remarkably, even if $p_{2}^{*}(\bar{p})$ is only slightly lower than $p_{1}^{*}(\bar{p})$, the move produces a seismic change: there is only one equilibrium, at $\bar{p}_{2}$, and it involves only a fraction as much parking as $\bar{p}_{1}$. The reason is that, in moving from $p_{1}^{*}(\bar{p})$ to $p_{2}^{*}(\bar{p})$, the upper part of the curve fell below $p=\bar{p}$, not because the tax increase from $\tau_{1}$ to $\tau_{2}$ was especially large.

\subsubsection{Coordination}

The above two policies influence landlords as individuals. It is also possible, in the case of multiple equilibria, for an authority to directly coordinate all parcels toward a desired equilibrium. The most straightforward way to do so is to develop a large number of empty parcels, all at once, to achieve an aggregate parking ratio in the vicinity of a chosen stable equilibrium. Planning movements such as New Urbanism could be be thought of as attempts to begin at a walkable equilibrium.

Planners could also attempt to shift an established neighborhood to a new equilibrium by providing sunspots. This term from macroeconomics refers to "phenomena that do not affect tastes, endowments or production possibilities" but that nonetheless have real effects by synchronizing beliefs 
(Cass and Shell 1983, p. 193). For example, an upbeat government report on the economy may induce businesses to invest and hire, even when it contains no original news. Businesses invest because they believe others will do so.

Similarly, municipal policies could act as sunspots, coordinating landlord's beliefs about the future state of the neighborhood. Consider the construction of a streetcar. Even if it fails to provide a good substitute for car travel, its presence may induce landlords to provide less parking by fostering a general understanding that the neighborhood is headed in a walkable direction. Landlords will thus provide somewhat less parking in expectation of this state of affairs, and in doing so fulfill the prophecy of a walkable neighborhood. It is not even essential that landlords have faith in the streetcar as a viable transportation option, only that they believe other landlords associate the streetcar with a walkable land-use pattern. Of course, a streetcar alone could never shoulder such a large burden, but the point is that its contribution, as part of a policy package, could be its power as a coordinator of private expectations.

\section{Conclusion}

This paper has drawn attention to the possibility of a feedback loop in the provision of off-street parking for neighborhoods where development is on-going and off-street parking may substantially alter urban form. After an introduction, Sec. 2 discussed feedback qualitatively, offering ways it could arise and distinguishing positive from negative feedback. Section 3 set up a stylized economic model of bundled parking, showed how individuals decide how much parking to provide in the model and inserted several policies.

The examples given can certainly not be expected to apply everywhere, and the actual process of neighborhood change rests on considerably more than the parking supply. Still, if academics and planners are trying to predict the course of a neighborhood or to explain the course one has already taken, the feedback potential of the competition between parking and floorspace could be worth considering. Parking is a major part of the cityscape, and developers do not make their decisions about parking in a vaccum. The examples have tried to make clear, in a concrete way, how the neighborhood's character and the small choices that decide it may be inexorably and plausibly tied together.

While the paper has mainly formalized policies, not judged them, the analysis should serve to sound a note of epistemic caution. Under simple assumptions, policies have been shown to have consequences that are difficult to predict from a survey of static conditions and interests. This point may be read as favorable to intervention in some cases and hostile in others. Against intervention is the argument that, though they may target real externalities like cruising for parking or spillover into private lots, parking regulations that carry even a slight danger of unwraveling or precluding a good land-use equilibrium merit scrutiny. In favor of intervention is the argument that past policy failures do not always foreshadow future results: a policy—such as a parking tax-may have very modest results until some threshold is breached. 


\section{References}

Barter, P. A. 2010. Off-Street Parking Policy without Parking Requirements: a Need for Market Fostering and Regulation? Transport Reviews, 30(5):571-588. ISSN 0144-1647. doi: 10.1080/01441640903216958.

Benabou, R. 1993. Workings of a city: location, education, and production. The Quarterly Journal of Economics, 108(3):619-652. ISSN 0033-5533. doi: 10.2307/2118403. URL http: //qje.oxfordjournals.org/content/108/3/619.short.

Cass, D. and K. Shell. 1983. Do Sunspots Matter? Journal of Political Economy, 91(2):193-227. ISSN 0022-3808. doi: 10.1086/261139. URL http://www.jstor.org/stable/pdf/1832054.pdf.

Cutter, W. B. and S. F. Franco. 2012. Do parking requirements significantly increase the area dedicated to parking? A test of the effect of parking requirements values in Los Angeles County. Transportation Research Part A: Policy and Practice, 46(6):901-925. ISSN 09658564. doi: 10.1016/j.tra.2012.02.012. URL http://www.sciencedirect.com/science/article/ pii/S0965856412000304.

Feitelson, E. and O. Rotem. 2004. The case for taxing surface parking. Transportation Research Part D: Transport and Environment, 9(4):319-333. ISSN 13619209. doi: 10.1016/j.trd.2004.04.002. URL http://www.sciencedirect.com/science/article/pii/S1361920904000240.

Ferguson, E. 2004. Zoning for Parking as Policy Process: A Historical Review. Transport Reviews, 24(May):177-194. ISSN 0144-1647. doi: 10.1080/0144164032000080485.

Granovetter, M. 1978. Threshold Models of Collective Behavior. American Journal of Sociology, 83(6):1420. ISSN 0002-9602. doi: 10.1086/226707.

Inci, E. 2014. A review of the economics of parking. Economics of Transportation. ISSN 22120122. doi: 10.1016/j.ecotra.2014.11.001. URL http://www.sciencedirect.com/science/ article/pii/S2212012214000562.

Jacobs, J. 1961. The Death and Life of Great American Cities. New York: Random House. ISBN 067974195X. doi: 10.2307/794509.

Jakle, J. A. and K. A. Sculle. 2004. Lots of Parking: Land Use in a Car Culture. Charlottesville: University of Virginia Press. ISBN 9780813922669.

Krugman, P. 1990. Increasing returns and economic geography. Jounral of Political Economy, 99(3):483-499. URL http://www.nber.org/papers/w3275.

Krugman, P. R. 2011. The new economic geography, now middle-aged. Regional Studies, 45(1):1-7. ISSN 0034-3404. doi: 10.1080/00343404.2011.537127. URL http://www.informaworld.com/ $10.1080 / 00343404.2011 .537127$.

Li, F. and Z. Guo. 2014. Do parking standards matter? Evaluating the London parking reform with a matched-pair approach. Transportation Research Part A: Policy and Practice, 67:352-365. ISSN 09658564. doi: 10.1016/j.tra.2014.08.001. URL http://www.sciencedirect.com/science/article/ pii/S0965856414001815.

Manville, M. 2013. Parking Requirements and Housing Development. Journal of the American Planning Association, 79(1):49-66. ISSN 0194-4363. doi: 10.1080/01944363.2013.785346. URL http://www.tandfonline.com/doi/abs/10.1080/01944363.2013.785346\{\#\}.VZWirBNViko.

Manville, M., A. Beata, and D. Shoup. 2013. Turning Housing Into Driving: Parking Requirements and Density in Los Angeles and New York. Housing Policy Debate, 23(2):350-375. ISSN 10511482. doi: 10.1080/10511482.2013.767851. URL http://www.tandfonline.com/doi/abs/10. 1080/10511482.2013.767851.

Manville, M. and D. Shoup. 2005. Parking, People, and Cities. Journal of Urban Planning and Development, 131(4):233-245. ISSN 07339488. doi: 10.1061/(ASCE)0733-9488(2005)131:4(233).

McCahill, C. and N. Garrick. 2014. Parking Supply and Urban Impacts. In S. Ison and C. Mulley, eds., Parking: Issues and Policies, volume 5, pp. 33-55. Emerald. doi: 10.1108/S2044-994120140000005017. URL http://www.emeraldinsight.com/doi/abs/10. 
1108/S2044-994120140000005017.

McDonnell, S., J. Madar, and V. Been. 2011. Minimum parking requirements and housing affordability in New York City. Housing Policy Debate, 21(November 2014):45-68. ISSN 1051-1482. doi: 10.1080/10511482.2011.534386.

Mukhija, V. and D. Shoup. 2006. Quantity versus Quality in Off-Street Parking Requirements. Journal of the American Planning Association, 72(3):296-307. ISSN 0194-4363. doi: 10.1080/01944360608976752.

Quercia, R. G. and G. C. Galster. 2000. Threshold Effects and Neighborhood Change. Journal of Planning Education and Research, 20:146-162. ISSN 0739-456X. doi: 10.1177/0739456X0002000202.

Schelling, T. C. 1971. Dynamic models of segregation. The Journal of Mathematical Sociology, 1(2):143-186. ISSN 0022-250X. doi: 10.1080/0022250X.1971.9989794. URL http://www. tandfonline.com/doi/abs/10.1080/0022250X.1971.9989794\{\#\}.VZWg7BNViko.

Shoup, D. 2005. The high cost offree parking. Chicago: Planners Press, American Planning Association. ISBN 9781884829987.

Weinberger, R., J. Kaehny, and M. Rufo. 2010. U . S . Parking Policies : an Overview of Management Strategies. Technical report, Institute for Transportation and Development Policy.

Willson, R. W. 1995. Suburban Parking Requirements: A Tacit Policy for Automobile Use and Sprawl. Journal of the American Planning Association, 61(1):29-42. ISSN 01944363. doi: 10.1080/01944369508975617. URL http://www.tandfonline.com/doi/abs/10.1080/ 01944369508975617. 